\title{
BMJ Open Challenges to achieving universal health coverage through community- based health planning and services delivery approach: a qualitative study in Ghana
}

\author{
Abraham Assan, ${ }^{1,2}$ Amirhossein Takian, ${ }^{1,3,4}$ Moses Aikins, ${ }^{5}$ Ali Akbarisari ${ }^{1}$
}

To cite: Assan A, Takian A, Aikins $\mathrm{M}$, et al. Challenges to achieving universal health coverage through community-based health planning and services delivery approach: a qualitative study in Ghana. BMJ Open 2019;9:e024845. doi:10.1136/ bmjopen-2018-024845

- Prepublication history for this paper is available online. To view these files, please visit the journal online (http://dx.doi org/10.1136/bmjopen-2018024845).

Received 16 June 2018 Revised 11 October 2018 Accepted 24 January 2019

Check for updates

(C) Author(s) (or their employer(s)) 2019. Re-use permitted under CC BY-NC. No commercial re-use. See rights and permissions. Published by BMJ.

For numbered affiliations see end of article.

Correspondence to Dr Amirhossein Takian; takian@tums.ac.ir

\section{ABSTRACT}

Objective Community-based initiatives have enormous potential to facilitate the attainment of universal health coverage (UHC) and health system development. Yet key gaps exist and threaten its sustainability in many low-income and middle-income countries. This study is first of its kind (following the launch of the Sustainable Developments Goal [SDG]) and aimed to holistically explore the challenges to achieving UHC through the communitybased health planning and service (CHPS) initiative in Ghana.

Design A qualitative study design was adopted to explore the phenomenon. Face-to-face indepth interviews were conducted from April 2017 until February 2018 through purposive and snowball sampling techniques. Data were analysed using inductive and deductive thematic analysis approach.

Setting Data were gathered at the national level, in addition to the regional, district and subdistrict/local levels of four regions of Ghana. Sampled regions were Central Region, Greater Accra Region, Upper East Region and Volta Region.

Participants In total, 67 participants were interviewed: national level (5), regional levels (11), district levels (9) and local levels (42). Interviewees were mainly stakeholders-people whose actions or inactions actively or passively influence the decision-making, management and implementation of CHPS, including policy makers, managers of CHPS compound and health centres, politicians, academics, health professionals, technocrats, and community health management committee members. Results Based on our findings, inadequate understanding of CHPS concept, major contextual changes with stalled policy change to meet growing health demands, and changes in political landscape and leadership with changed priorities threaten CHPS sustainability. Conclusion UHC is a political choice which can only be achieved through sustainable and coherent efforts. Along countries' pathways to reach UHC, coordinated involvement of all stakeholders, from community members to international partners, is essential. To achieve UHC within the time frame of SDGs, Ghana has no choice but to improve its national health governance to strengthen the capacity of existing CHPS.
Strengths and limitations of this study

- The stratified data collection strategy and the variety of study participants from across different levels and settings helped gain a broader understanding of the phenomenon.

- Our framework enabled us to accommodate a wide range of disciplines for pragmatic interpretation of the phenomenon, by exploring different components of the community-based health planning and service initiative.

- To enhance the credibility of our study, we explored the phenomenon through various lenses (ensuring triangulation), performed member check, ensured transparency of methods and analysis, and involved multiresearchers from different backgrounds.

- Although this study is the first of its kind and has used a robust methodology, we cannot be certain of participants' underlying rationale for responding, especially with regard to their political, institutional and societal commitments towards the initiatives; hence, like any qualitative study, our findings need to be interpreted with some caution.

\section{INTRODUCTION}

Today, a big proportion of health policy debate is focused on accomplishing the 2030 Sustainable Development Agenda, a milestone which places specific importance on universal health coverage (UHC) - a concept which supports a collective credence that all people should have access to the health services they need without risk of financial ruin or impoverishment. ${ }^{1}$ Nonetheless, considering the existing disparities within countries, achieving UHC will require all-inclusiveness and participatory interactions between health systems and the citizens. ${ }^{2-4}$ As a result, community health system performance has become increasingly relevant to both high-income countries and low-income and middle-income countries (LMICs). 
Ghana, in 2000, launched the community-based health planning and service (CHPS) initiative to facilitate the achievement of the vision based on the premise that UHC can be achieved if improved health services are delivered closer to the doorstep of community members, particularly to those at the rural and slummy areas. Under this initiative, community health professionals, supported by community volunteers, are trained to provide healthcare in a CHPS zone (geographical coverage areas for community health services-presently, about 5487 zones in number).$^{5}$ Key service package includes maternal and reproductive health, child health services, treatment of minor ailments, health education and promotion of healthy lifestyles, and follow-up on clients. ${ }^{67}$

CHPS has created one of the best approaches in increasing community commitments and ownership towards health system strengthening, enhancing equitable access and delivery of primary healthcare (PHC), and resources mobilisation. ${ }^{8}$ Yet many challenges persist and threaten the success and sustainability of the initiative, including inadequate financial resources, poor management and supervision of programmes, insufficient health infrastructure, physical inaccessibility, inadequate trained community health workforce, high attrition rate, sociocultural beliefs, and poor referral system. ${ }^{9}$ In this study, we aimed to enhance the understanding of the challenges limiting the effective role of CHPS in contributing to achieving UHC in Ghana. We used a theoretical framework (the Walt and Gilson's policy triangle) to guide the interpretation of findings. This research is the first of its kind. We anticipate that our findings could facilitate the achievement of Sustainable Development Goals (SDGs), UHC in particular, in Ghana, and perhaps many other LMICs.

\section{METHODS}

\section{Study design, settings, sampling and data collection}

The qualitative study design was used to explore the phenomenon. The study was conducted in four regions of Ghana to represent diversity in terms of socioeconomic status, cultural, religion, geographical position and level of performance of CHPS in the country. ${ }^{6} 1011$ The sampled regions were Central Region, Greater Accra Region, Upper East Region and Volta Region. Data were gathered at four levels-national, regional, district and local levels-to ensure triangulation. ${ }^{12}$ A purposive and snowball sampling technique was employed to identify study participants at the national and regional levels. ${ }^{13}$ At the district and local levels, participants were sampled through the snowball technique. ${ }^{14}$ Three university graduates with experience in research were recruited and trained to assist in data collection. Training lasted for 3 days. Pretesting of data collection instruments was done during the training session.

Face-to-face indepth interviews were conducted from April 2017 until February 2018. Interviews were conducted in English. Separate semistructured interview guides were designed for interviews at each level. Data were gathered until saturation, where we realised no new data were emerging. ${ }^{15}$ Interviews lasted between 25 and $45 \mathrm{~min}$. In total, 67 participants were interviewed: national level (5 interviewees), regional levels (11 interviewees), district levels (9 interviewees) and subdistrict/local levels (42 interviewees) (refer to table 1 for list of interviewees and their characteristics and study settings). Interviewees were mainly stakeholders-people whose actions or inactions actively or passively influence the decision-making, management and implementation of CHPS. They include policy makers of the CHPS initiative, managers of CHPS compound and health centres, politicians, academics, health professionals, technocrats, and community health management committee members. Addition to the interviews were document review and observation.

\section{Data analysis}

All interviews were audio-recorded, and the data gathered were transcribed verbatim. Coding was done manually. We used Walt and Gilson's policy triangle to guide data analysis. This framework was selected because it has influenced health policy research in a diverse array of countries and has been used to analyse several health issues and health sector reform, which is appropriate in the context of our study. The framework enabled us to explore the perspectives of the different components of the CHPS initiative, with regard to how the content of policy, neglecting actors, context and processes interact to shape policy making. ${ }^{16}$ Further, we remained open to accommodate other emerging themes; hence, we employed the hybrid interactive processes of inductive and deductive thematic analysis to interpret our data. ${ }^{17}$

Codebooks were developed, and themes that emerged from the data were repeatedly reviewed using the research questions. To enhance trustworthiness of findings, two research members (AA, MA) were assigned to do first coding (open breakdown of themes). This enabled us to identify all prevailing themes in the study. Next, AT and AAS created intercode connections among themes. Relevant codes which were associated with study objectives were extracted, compared and discussed among members. Similarities and differences between codes were also addressed. ${ }^{18}$

Next, through thorough content analysis, we interpreted the categorised themes which were relevant to the accomplishment of the objectives of the study. That is, we read the documents and transcripts repeatedly (got immersed with the data), performed member checks and coded them inductively and deductively, followed with iterative analysis. This enabled us to understand and interpret extracted themes, which were centred on and relevant to the CHPS initiative. Finally, core categorical themes were selected, analysed and compared with existing literature to ensure the reliability, validity and comprehensiveness of our findings (selective coding). ${ }^{18}$ Final codes were developed based on consensus of the entire research team (AA, AT, MA, AAS). 
Table 1 List of interviewees and study settings

\begin{tabular}{|c|c|c|c|c|c|}
\hline Region levels & Central Region & $\begin{array}{l}\text { Greater Accra } \\
\text { Region }\end{array}$ & Upper East Region & Volta Region & Total \\
\hline National level & \multicolumn{4}{|c|}{$\begin{array}{l}\text { Head of CHPS (1), head of monitoring and evaluation (1), other senior officials (2) at policy, planning, } \\
\text { monitoring and evaluation unit at the Ministry of Health, and renowned researcher on CHPS (1). }\end{array}$} & 5 \\
\hline Region levels & $\begin{array}{l}\text { Cape Coast } \\
\text { Deputy regional director for } \\
\text { health administration and support } \\
\text { services (1); regional director for } \\
\text { public health (1); senior public } \\
\text { health nurse (1); head of service } \\
\text { training (1); regional health } \\
\text { information officer (1); regional } \\
\text { human resource manager (1). }\end{array}$ & $\begin{array}{l}\text { Accra } \\
\text { Regional CHPS } \\
\text { coordinator and } \\
\text { deputy director of } \\
\text { nursing services (1). }\end{array}$ & $\begin{array}{l}\text { Bolgatanga } \\
\text { Regional CHPS } \\
\text { coordinator (1); } \\
\text { senior reproductive } \\
\text { and child health (1); } \\
\text { information officer (1). }\end{array}$ & $\begin{array}{l}\text { Ho } \\
\text { Regional CHPS } \\
\text { coordinator(1). }\end{array}$ & 11 \\
\hline $\begin{array}{l}\text { District/Municipal } \\
\text { levels }\end{array}$ & $\begin{array}{l}\text { Assin North District } \\
\text { Municipal health director (1); } \\
\text { municipal CHPS coordinator } \\
\text { (1); municipal nutrition technical } \\
\text { officer (1); community mental } \\
\text { health officer (1). }\end{array}$ & $\begin{array}{l}\text { Kpone Katamanso } \\
\text { District } \\
\text { District health } \\
\text { director (1). }\end{array}$ & $\begin{array}{l}\text { Bolgatanga Municipal } \\
\text { and Kassena } \\
\text { Nankana West District } \\
\text { Municipal CHPS } \\
\text { coordinator (1); } \\
\text { district CHPS } \\
\text { coordinator (1); } \\
\text { nursing officer (1). }\end{array}$ & $\begin{array}{l}\text { Ho Municipal } \\
\text { Municipal CHPS } \\
\text { coordinator (1). }\end{array}$ & 9 \\
\hline $\begin{array}{l}\text { Subdistrict/Local } \\
\text { levels }\end{array}$ & $\begin{array}{l}\text { Assin Endwa CHPS compound } \\
\text { Community health nurse (CHN) } \\
\text { (1); head of facility (1); enrolled } \\
\text { nurses (EN) (1); community } \\
\text { health management committee } \\
\text { (CHMC) - traditional leader (chief) } \\
\text { (1), assembly member (1); other } \\
\text { opinion leaders (2). }\end{array}$ & $\begin{array}{l}\text { Appolonia CHPS } \\
\text { compound } \\
\text { General nurse (1); } \\
\text { CHN (1); midwife } \\
\text { (1); EN (1); nursing } \\
\text { officer (1); CHMC- } \\
\text { traditional committee } \\
\text { (2), assembly } \\
\text { member (1); other } \\
\text { opinion leaders (3). }\end{array}$ & $\begin{array}{l}\text { Yikene and Nania } \\
\text { CHPS compound } \\
\text { CHN (1); EN (2); } \\
\text { Community health } \\
\text { officer (CHO)(2); } \\
\text { community health } \\
\text { worker (CHW) (3); } \\
\text { midwife (1); CHMC- } \\
\text { traditional leader (1), } \\
\text { religious leader (1), } \\
\text { assembly member } \\
\text { (1), community youth } \\
\text { volunteer (2). }\end{array}$ & $\begin{array}{l}\text { Loboli and Atikpui } \\
\text { CHPS compound } \\
\text { EN (3); head } \\
\text { of facility (2); } \\
\text { CHOs (2); CHW } \\
\text { (2); CHMC- } \\
\text { community youth } \\
\text { volunteer (1). }\end{array}$ & 42 \\
\hline
\end{tabular}

CHPS, community-based health planning and service initiative.

\section{Patient and public involvement}

This qualitative study focused on a nominated public health initiative (CHPS) through the lenses of policy, whose participants were mainly policy makers, managers and the representatives of the public who were not conventionally classified as patients recruited for medical research. Nonetheless, the key actors were widely consulted in the development of the research questions and in assessing the implications of the findings. Further, findings will be disseminated through stakeholders' events (including one-on-one policy talk show) to enhance the significance and salience of findings.

\section{RESULTS}

The CHPS initiative was found in 2000 to facilitate the achievement of UHC by providing improved health services, mainly preventive, promotive and treatments of minor ailments, closer to the doorstep of community members, particularly to those at the rural areas-efforts aimed to address geographical barriers to health. Although CHPS has created one of the best approaches in increasing communities' commitments towards health system strengthening, its performance has declined over the years. According to our findings, inadequate understanding of the CHPS concept, major contextual changes with stalled policy change to meet growing health demands, and changes in political landscape and leadership with changed priorities threaten CHPS sustainability.

\section{Inadequate understanding of the CHPS concept}

CHPS has been in existence for over 18 years. Yet the concept of CHPS has not been fully gripped by major stakeholders, most importantly political institutions and community members. To achieve universal access to healthcare in Ghana, CHPS remains ideal-serving as a vehicle not just for delivering healthcare, but to the very doorstep of the client. Nonetheless, according to our findings, major actors operate but at varying degrees to achieve personal interests-not necessarily to contribute 
to achieving the key mandate of CHPS. That is, political bodies, through active collaboration with district assemblies, construct CHPS compounds for political gains-that is, to solicit for votes, sometimes without even consulting the health directorate. As a result, most CHPS structures do not meet the required building plan, while others are not strategically situated to address the geographical barriers to accessing healthcare-a primary goal the initiative seeks to achieve.

\section{In fact, I should state that some stakeholders don't really understand the role as far as CHPS initiative is concern. Politicians one way or the other think we should construct CHPS compounds where they had won votes. Some even go to the extent of constructing CHPS facility without prior con- sultation from the health directorate, which at the end are not being patronized by the clients because it may be either at the outskirt of the town where health officers find it difficult to reside there or where it's too far from clients. - Municipal Health Director (Central Region)}

Our findings also revealed the community entry processes were not properly carried out from the onset, influencing many implementation flaws. For example, community members routinely demand of services which do not form part of the service package of CHPS, and often beyond the capabilities of the community health professions. That is, communities consider CHPS to be a health centre or a hospital, hence expect health professionals to be able to provide a more comprehensive service.

\section{the concept of CHPS is still not well understood by a bigger session of the community - clients today still perceive that when you talk of health, it is getting sick and being treated. They least understand the CHPS concept emphasizes more on health promotion and prevention. Due to that, you may get up in the morning with plans to go for home visit (for health talk) just to find clients in queues demanding for medical treatments - including services which we are not even permitted to render. I think once the people know that the policy is to prevent them from being sick, then of course, they won't wait till they are sick and then be running to the health facilities —Community Health Officer (Upper East Region)}

Again, members of the community were not made to fully understand that CHPS is community-driven and therefore its success greatly depends on the community. Community members were of the belief that the government should be solely responsible for the total establishment and management of CHPS. In view of that, there is a growing perception that CHPS is a strategy used by the government to shift their core responsibilities to its citizens, given that the initiative is community-induced. Besides, as observed, majority of amenities of most facilities were either provided by the community and non-governmental organisations (NGOs) (especially the international donors).
We have been convinced to build our own health facility, advocate for the provision of health amenities and logistics, and pay our utilities, what then is the role of the government if health development of a community is to be exclusively provided by the community? -Community Leader (Greater Accra Region)

Major contextual changes, with ensuing stalled policy change to meet growing demands

CHPS is currently faced with major contextual changes, with ensuing stalled policy changes to address current health needs and expectations of the communitiesmainly due to inadequate dedicated resources to sustain the initiative and rigid organisational framework.

Over a decade ago, people were travelling long distances to access health, and therefore there was the need to send services to the rural areas, through which CHPS was originally birthed to primarily provide services at the doorsteps of households. CHPS compounds were strategically erected in selected communities to facilitate service provision, where community health professionals were tasked to provide door-to-door services to communities including those without a CHPS compound. Nevertheless, today, despite being a national policy for all electoral areas to have a CHPS compound, almost all communities demand CHPS compound to be constructed in their communities, many of which are even putting up structures without government support. However, according to our study, the existence of a 'physical CHPS structure' has implied increasing health demand by community members, as clients perceive it as a hospital. Hence, the present demand and expectations of communities extend beyond the services package of CHPS, which is mainly preventive, promotive and treatment of minor ailment. Based on our findings, community members on constructing a CHPS compound would want CHPS to function as a health centre or a hospital, and demand for extra health departments especially maternal health units-aspirations which are barely difficult to peruse considering the aim of CHPS. Besides, the rising health demands and the willingness of communities to expand the service package of CHPS exact much pressure on the governments, largely due to unplanned resources to sustain the initiative. As a result, CHPS facilities lack basic logistics and medicines needed to treat minor ailments. This has led to rampant referral of health cases to either the health centre or the hospital. Yet neither of the CHPS compounds across all the regions even had an ambulance to facilitate referral processes. Health professionals had to rely on commercial vehicles and motorcycles during referrals, and even with that, aside from not being appropriate for referrals, these vehicles are often either far away from CHPS compounds to render immediate service or clients do not have the money to pay for the fare, leaving the financial burden on the health professionals.

....CHPS is expanding at rate governments are not able to cope. The request for new facilities or units implies that 
the government need to increase the provisions for logistics, employ more staffs, pay workers their remunerations etc. Meanwhile, the budget for the sector is not growing at a rate we are expected to spread our services. Yes, our main objective is to improve access, but we are limited due to inadequate resources. - Senior Policy Maker (national level)

Moreover, improved knowledge is changing health practices especially among urban residents. Yet CHPS is faced with inadequate resources for capacity building of community health professionals, to fully meet health needs and expectations, and to match the changing health practices of their clients. To this end, urban residents especially evinced a negative attitude towards community health professions (particularly health volunteers), questioning their credibility to educate them about health.

I was first working in a rural community, but we were recently reshuffled and was posted to the city. Fairly speaking, I prefer to work in the rural areas. You see my entire work is to promote health or educate the community about health. But within the city, the residents are knowledgeable. Some even refuse to listen to our health talk because they feel they are well informed even than the community health experts. Besides, they get any information they need on the internet. But working as a health officer in the rural areas is quite a different. I remember when I was first posted to my previous workplace (village), the entire community was exceedingly glad to have us. But in the city, in fact their responses to our questions are something demoralizing. I think, the training that I acquired was very useful to me when I was working in the village but the situation in the city is quite different. -Community Health Officer (Volta Region)

Additionally, 18 years ago, it might be relatively easier to reach all community members or villagers in person and in groups. According to our study, health professionals lack the appropriate mobilisation skills to successfully organise health durbars. Again, there is a limited use of digital tools in ensuring that community members irrespective of place and time do have consistent access to health information. Further, while volunteerism was found fundamental in CHPS sustainability, the concept, although properly understood by community members, has been met with strong resistance, where volunteers today demand salaries for their services. According to volunteers, "it is very discouraging getting up every morning for work and at the end of the month you end up receiving no salary. I have been a community volunteer for over 15 years, yet I cannot boast of significant reward for my work. I understand I volunteered for this kind of work but mind you I also have families."

Currently, it is difficult mobilizing community members for health durbars. Most of them are engaged with economic activities - hence leave very early for farms (work) and return late. Also, community participation was initially stronger because we had active volunteers supporting our work. But today, volunteerism is no more, and is really affecting our work. -Community Health Officer (Upper East Region)

\section{Changes in the political landscape and leadership with changed priorities}

Complex interactions of actors were found to have a critical influence on CHPS. To our participants, although a broader political process is required for CHPS sustainability, recent commitments of political bodies towards CHPS are not up to expectation. Every government comes with its own priorities-nobody continues from where the previous government ended. What governments have commonly done is to construct CHPS compoundsleaving behind provision of logistics-since the number of compounds built is often considered as major political achievements. Also, although our study revealed a more prevailing commitment by the community members and the international donors to improve CHPS, while communities lack the needed resources to sustain the initiative, policy inconsistency also threatens the sustainability of projects pursued by international donors. That is, these international bodies mostly implement pilot projects for a stipulated time and then leave, but who to commit to the course left behind and provide the desired resources to sustain the initiative is a challenge which retards the progress of CHPS.

CHPS is more a political tool now - it is just on the lips of our politicians. They promise a lot but deliver little. When it comes to logistics, we often rely on donor partners who mostly come to pilot projects for a stipulated time and then leave. But whether such projects are sustained is another issue because when they pull-out who to continue from wherever they ended is also a unique challenge altogether. Nonetheless, if the leaders are so vibrant and active, you see them going in and out sourcing for funding to sustain the initiative. But you wouldn't see that in places where the leaders do not believe in the concept of CHPS. So, there will be a bit of variation in the level of performance depending on who for example is the head, and more to the point where the developing partners seek to work. This is part of the reason why some regions have several partners helping to improve CHPS, and otherwise. So, that might resort to a bit of disparity in performance, but when you talk about challenges faced by the initiative due to governmental commitments, then that tends to be a countrywide challenge. - Renowned Researcher on CHPS

Furthermore, we found communities' independent efforts being driven by loss of trust in the governments to fully provide their health needs. To the community members, governments have shown inadequate exertion to provide CHPS compounds the basic resources. Hence, any initiative where communities can lead the forefront of their development and not to always rely on the government is worthy to embrace. In view of that, community leaders and members with improved understanding of the CHPS concept independently 
exhibited vigorous efforts towards issues of health and development.

We never waited for the Ghana Health Service to inform us that we are due for CHPS compound. That would have taken a long time, considering the political processes involved. The community has formed an alliance with a UK based Trust that support our development. So, we proposed to them to also support the establishment of our facility, and over fiveyears the community has also been contributing to pay the utilities of the facility. - Traditional Leader (community chief) (Central Region)

On the other hand, where there were chieftaincy disputes, key stakeholders (especially traditional leaders) oppose decision-making processes and programme implementation. As an example, we observed low community participation in communities facing chieftaincy and land disputes, or without a chief-since health professionals find it difficult identifying which leader to consult to serve as a focal point to engage its citizens. Also, due to lack of consensus, family members and friends of opposing leaders also refuse to attend programmes being organised for the community.

Communities are encountering series of chieftaincy and land disputes. As a result, you may organize a health durbar in one community, and it will interest you to know that part of the community members will deliberately not attend, expecting a separate durbar to be conducted for them. The reason being that, opposing leaders would want to be also recognized and treated as community heads. Unlike elsewhere, where you find out that a community has just one chief (leader) who perhaps may serve as the head of the CHPS zone to engage its citizens. -Community Youth Volunteer (Volta Region)

\section{DISCUSSION}

The Alma-Ata Declaration of 1978 identified the role of a comprehensive PHC as the cornerstone to any sustainable health system. Now, in its 40th anniversary, while the philosophy of PHC is valid more than ever, the development of PHC-based healthcare delivery has received a paradigm shift towards the deployment of several forms of community health workers (CHWs) — as cadres capable of delivering effective care at the least cost, at the community and household levels. ${ }^{19}$

Social mobilisation and community participation need to be at the centre of health policy planning and implementation to achieve UHC in any setting. Ultimately, the efficiency of the community health volunteers and managers (including community health management teams) through regular capacity building and constant training for building more effective and responsive systems to adapt the dynamic changing health needs are the keys to the success of community-based programme. Well-designed, community-driven initiatives have proved capable of establishing a more substantial means in addressing crippling PHC system in several LMICs. For instance, addressing shortage and poor distribution of various health workers and encouraging them to choose to practise in rural and underserved areas, expanding and strengthening coverage of key health programmes, and reorganising health workforce to address challenges pertaining to low access to quality, people-centred, affordable and acceptable healthcare services can be mentioned. ${ }^{19}$ The 'Behvarz' of Iran, the village health volunteers in Thailand, the lay health workers in Pakistan, the health extension workers in Ethiopia and Building Resources Across Communities (BRAC) in Bangladesh are all successful community-based models ${ }^{20}$ which have contributed immensely towards programmes focused on maternal, neonatal, child healthcare and development, and reproductive health.

Yet, even in countries with proved and meaningful success, key challenges continue to threaten the sustainability of such initiatives. Community-based programmes necessitate active engagements of actors. However, often, stakeholders operate without robust mechanism for coordination, which may hinder achieving the intended purposes. As our study reveals, this challenge might emerge because of inadequate understanding of the policy content, and the lack of equal cooperation among major actors including political bodies, donors, the health directorate and the local partners at the district and subdistrict levels.

Conflicting stakeholder interests (especially among politicians) have led to a several disorganised national debate, particularly during establishment or expansion of public health services. ${ }^{21}$ Hence, politics and stakeholders' engagements matter at each phase of health reformas existing institutions and interest groups often have both the reasons and the resources to vigorously oppose change, ${ }^{22}$ as experienced for instance by the Iranian health system where medical doctors initially opposed family physician programme in rural Iran due to lack of prior consultation and understanding of policy content. ${ }^{14}$ Notwithstanding that, community participation in all aspects of policies is essential to enhance sustainability through country ownership and accountability. ${ }^{323}$ Otherwise, promoting local ownership of initiatives would become challenging, as it happened in Brazil. ${ }^{24}$

The key to attaining UHC through community-based programmes is the ability of global, national and local partners to ensure much policy flexibilities, especially at the local levels. ${ }^{20}$ However, our research revealed that the CHPS initiative is increasingly becoming complex and difficult to manage, due to its openness to change and the increasing diversity of demand and expectations of clients. Any pressing demand is considered critical and a potential target for reform, although it might not be strategic implementing such initiative at that level of care. As an example, the increasing demand of maternity unit has raised varying views among stakeholders as to whether all CHPS facilities need to have a delivery ward, or clients should be referred to the next level of care. Worse still, 
the component of minor treatments within the service package has rendered the initiative less effective and efficient, and eventually is causing the community members to lose trust in community-based health system. Let alone that, despite the rising demand and expectations, CHPS is challenged with inadequate resources (even basic logistics) to treat minor ailments, which has led to rampant referrals of health cases and its associated costs. Hence, we are of the view that CHPS can achieve eloquent results if efforts are geared towards improving preventive and promotive services, rather than curative care. Besides, due to inadequate resource allocation by the governments, adding facilities and interventions (a midwifery delivery department at the facility, in the case of our study) will lead to further unanticipated malfunctions of the system. ${ }^{25}$ In addition, as societies modernise and become more affluent and knowledgeable, what people consider to be desirable ways of living as individuals and as members of societies may change. ${ }^{26}$ Yet the CHPS initiative is faced with lack of resources to help build the capacity of community health professionals, particularly regarding the use of tools in responding to changes in health practices, to enhance better community participation and mobilisation, as well as efficiency. As a result, clients, especially the urban residents, show negative attitudes towards community health professions (especially health volunteers), questioning their credibility to even educate them about health. Notwithstanding that, these challenges could also serve as a platform for change and innovations. Yet it might lead to excessive dependence on international donors and NGOs-considering the limited political commitments in sustaining the initiative. This may in turn place immerse strains on communities, particularly the ones with the least resources to support themselves and meet challenges, which may reduce health performance, as happened in other settings. ${ }^{26}$

Generally, the governments' struggle to resolve what they are willing to spend resources on and what clients want is a fundamental health sector reform dilemma. ${ }^{27}$ Many LMICs are faced with the maldistribution of resources in the face of pressing health needs-where public sector is often perceived as providing inferior service, and many citizens, even the poor, may have to pay for improved services out of pocket, resulting to a varying degree of service and health status between urban and rural residents, and the rich and poor. ${ }^{21}$ In this respect, many countries that are even noted for sustainable community-based programmes may be affected by the effect of increase in workload on the community health professionals, which in turn can compromise the quality of health services they provide. ${ }^{28}$ Nevertheless, although resources matter, countries like Cuba have shown that better health chances can be achieved without the best of resources being available. It is recommended that healthcare financing for dispersed inhabitants often receive larger per capita expenditure, and in countries with both high-density and low-density populations it is expected that dispersed populations receive subsidy to promote equity. ${ }^{29}$ In addition, countries are devising cost-effective innovations that meet the health and well-being of its citizens from an explicitly multisectoral perspective, with a focus on expanding coverage of curative healthcare, while reinforcing promotive strategies and cross-sectoral actions on social determinants of health (SDH) ${ }^{30}$ Although that tends to be expensive, communities can secure such inputs at a manageable cost by joining forces. ${ }^{31}$ Our study revealed that communities that are making meaningful advancement through the CHPS initiative are those that are either resourced or have leaders constantly negotiating for support from non-governmental institutions. Further, the use of radio communications has shown success in overcoming geographical obstacles to health in such areas, in a more efficient and affordable manner. ${ }^{29}$

CHWs have featured in the discourse of many global public health agenda, by proving effective in addressing issues that have adverse impact on moving towards UHC. Today, in the era of Sustainable Developments Goals (SDGs), health is considered a political choice, and everyone's concern to drive the world to a state where health must be universal and equitable. ${ }^{32}$ Nonetheless, to achieve meaningful results, it is edged that countries adapt specific targets and actions based on national priorities that promote country ownership and accountability, ${ }^{23}$ reaffirming the profound role of community-based programmes in many LMICs, ${ }^{33}$ including Ghana.

\section{Policy recommendations to increase the chance of success}

Community-based initiatives are increasingly represented as a potential strategy to strengthen PHC. Nonetheless, certain vital gaps still impede their progress. Based on our findings, the following are recommended for community-driven initiatives to better help serve its purposes.

- Effective coordination and transparency among actors, particularly community members, NGOs, politicians and the health directorates, is eminent to enhance understanding of policy content and the ways in which changed priorities or conflicting institutional goals and values could emerge, to influence intended policy outcome.

- There is the need for effective ambulance services to facilitate upward referral of health services which are beyond the scope of community health professionals.

- Stakeholders, especially academic institutions, the community and governments, should create a sustainable framework to improve SDH and capacity building on the effective use of digital tools and community mobilisation skills, to shape public health practices.

Further studies are required to:

- Explore digital tools that can help improve knowledge of community health professionals, enhance community participation/mobilisation and health practices and interventions, and can foster greater accuracy and efficiency of activities.

- Identify ways in which factors such as the quality of community health governance and policy coherence can be maximised. 
- Investigate ways to provide sustainable community health financing and resource mobilisation.

\section{CONCLUSION}

UHC is a growing concern and a core target of the SDGs. Nonetheless, considering the existing disparities between and within countries, attaining UHC will necessitate all-inclusiveness, a participatory process and interaction between health systems and the populations. This has led to a renewed relevance of CHPS in Ghana-an initiative which practically relies on citizen engagement as a central instrument in the delivery of services closer to the doorstep of clients, particularly to those at the rural or slummy areas. Despite its recognition in safeguarding communities' commitments and country's ownership to attain UHC, gaps continue to impede its success. They include inadequate understanding of the CHPS concept-much of which is due to poor community entry and sensitisation programmes during the onset of CHPS scale-up. Again, major contextual changes, with ensuing stalled policy change to meet growing demands, and changes in the political landscape and leadership, with changed priorities or opposing forces, all threaten CHPS sustainability. Our study concludes that what is essential to influence positive change for achievements of UHC in Ghana (through CHPS) is the political will-an improved national health governance and the political determinants to lead actions of the community and international donors.

\section{Author affiliations}

${ }^{1}$ Department of Health Economics and Management, School of Public Health, Tehran University of Medical Sciences, Tehran, Iran

${ }^{2}$ Global Policy and Advocacy Network (GLOOPLAN), Accra, Ghana

${ }^{3}$ Department of Global Health and Public Policy, School of Public Health, Tehran University of Medical Sciences, Tehran, Iran

${ }^{4}$ Health Equity Research Centre (HERC), Tehran University of Medical Sciences, Tehran, Iran

${ }^{5}$ College of Health Science, School of Public Health, University of Ghana, P. 0. Box LG 13, Legon, Ghana

Acknowledgements We wish to acknowledge the Ministry of Health-Ghana, the Ghana Health Service and our study participants for their cooperation. We are also grateful to Emmanuel Adutwum, Ellen Hosi, Desmond Otsiabah, Juliet Letsu, Leonard Leonie Sumabe, Ibrahim Muctar, Francisca Korsa, Isaac Assan, Emmanuel Nana Asare Bempong, Latif Baako, Dzigbodi K. Hosi, and Dennis A. Adu Gyamfi, for supporting the study.

Contributors AA conceived the study, served as the principal investigator and drafted the manuscript. AT contributed to the conception of the study, supervised the entire process of design, data interpretation and analysis, and the intellectual development of the manuscript. He is the guarantor. MA also contributed to the conception of the study, assisted in data collection and development of the manuscript, and technically reviewed the article. AAS contributed to the conception of the study and the intellectual development of the paper. All authors read and approved the final manuscript.

Funding This work was supported by Tehran University of Medical Sciences (grant number 9413476002) and Global Policy and Advocacy Network (GLOOPLAN), Accra, Ghana.

\section{Competing interests None declared.}

Patient consent for publication Not applicable.

Ethics approval This study was first approved by the Ethics Committee of Tehran University of Medical Sciences (code: IR.TUMS.VCR.REC.1395.1699), followed by the Ghana Health Service Ethical Review Committee (registration number:
GHS-ERC: 08/03/2017). Further, we acquired written permission from the regional and district levels of all study settings, before commencing data collection. We also obtained written consent from all participants and guaranteed them of their privacy, confidentiality and anonymity of any information they provide. Participation was voluntary and without any compensation. Participants were given the right to opt out of the study at any point.

Provenance and peer review Not commissioned; externally peer reviewed.

Data sharing statement For extra data contact the corresponding author through takian@tums.ac.ir.

Open access This is an open access article distributed in accordance with the Creative Commons Attribution Non Commercial (CC BY-NC 4.0) license, which permits others to distribute, remix, adapt, build upon this work non-commercially, and license their derivative works on different terms, provided the original work is properly cited, appropriate credit is given, any changes made indicated, and the use is non-commercial. See: http://creativecommons.org/licenses/by-nc/4.0/.

\section{REFERENCES}

1. Organization WH. The world health report 2013. Research for universal health coverage. Geneva: WHO, 2014.

2. Smith J. Transnational processes and movements: The Blackwell companion to social movements, 2004:311-35.

3. London L. What is a human-rights based approach to health and does it matter? Health Hum Rights 2008;10:65.

4. Takian A, Akbari-Sari A. Sustainable health development becoming agenda for public health academia. Iran J Public Health 2016;45:1502.

5. GHS. Ghana Health Service Annual Report: GHS, 2014.

6. Awoonor-Williams JK, Sory EK, Nyonator FK, et al. Lessons learned from scaling up a community-based health program in the Upper East Region of northern Ghana. Glob Health Sci Pract 2013;1:117-33.

7. Adongo PB, Phillips JF, Aikins M, et al. Does the design and implementation of proven innovations for delivering basic primary health care services in rural communities fit the urban setting: the case of Ghana's Community-based Health Planning and Services (CHPS). Health Res Policy Syst 2014;12:1.

8. Sakeah E, McCloskey L, Bernstein J, et al. Is there any role for community involvement in the community-based health planning and services skilled delivery program in rural Ghana? BMC Health Serv Res 2014;14:340.

9. $\mathrm{MOH}$. Policy brief of community-based health planning and services (CHPS)- Ghana. http://www.moh- ghana.org/UploadFiles/ Publications/policy\%20brief\%20on\%20CHPS2130109060128.pdf. 2012 (Accessesd 23rd Apr 2016).

10. Awoonor-Williams JK, Bawah AA, Nyonator FK, et al. The ghana essential health interventions program: a plausibility trial of the impact of health systems strengthening on maternal \& child survival. BMC Health Serv Res 2013;13 Suppl 2:1.

11. MOH. National community-based health planning and service (CHPS) policy. MOH, Ghana: Accelerating Attainment of Universal Health Coverage and Bridging the Access Inquity Gap, 2016.

12. Silverman D. Interpreting qualitative data: methods for analyzing talk: Text and interaction Sage, 2006.

13. Patton M. Qualitative research and evaluation methods. (Rev. ed of: Qualitative evaluation and research methods. 2nd edn. Thousand Oaks: Sage, 2002.

14. Takian A, Doshmangir L, Rashidian A. Implementing family physician programme in rural Iran: exploring the role of an existing primary health care network. Fam Pract 2013;30:551-9.

15. Creswell JW. Qualitative inquiry and research design: choosing among five approaches: Sage, 2013.

16. Gilson L, Raphaely N. The terrain of health policy analysis in low and middle income countries: a review of published literature 1994-2007. Health Policy Plan 2008;23:294-307.

17. Fereday J, Muir-Cochrane E. Demonstrating rigor using thematic analysis: a hybrid approach of inductive and deductive coding and theme development. Int J Qual Methods 2006;5:80-92.

18. Corbin JM, Strauss A. Grounded theory research: Procedures, canons, and evaluative criteria. Qual Sociol 1990;13:3-21.

19. Glenton C, Colvin CJ, Carlsen B, et al. Barriers and facilitators to the implementation of lay health worker programmes to improve access to maternal and child health: qualitative evidence synthesis. Cochrane Database Syst Rev 2013;10:CD010414.

20. Tulenko K, Møgedal S, Afzal MM, et al. Community health workers for universal health-care coverage: from fragmentation to synergy. Bull World Health Organ 2013;91:847-52. 
21. Roberts M, Hsiao W, Berman P, et al. Getting health reform right: a guide to improving performance and equity: Oxford university press, 2003.

22. Wilsford D. States facing interests: struggles over health care policy in advanced, industrial democracies. J Health Polit Policy Law 1995;20:571-613.

23. Buse K, Hawkes S. Health in the sustainable development goals: ready for a paradigm shift? Global Health 2015;11:11(1):1.

24. Martinez J, Ro M, Villa NW, et al. Transforming the delivery of care in the post-health reform era: what role will community health workers play? Am J Public Health 2011;101:e1-5.

25. Mate KS, Sifrim ZK, Chalkidou K, et al. Improving health system quality in low- and middle-income countries that are expanding health coverage: a framework for insurance. Int J Qual Health Care 2013;25:497-504.

26. Inglehart R, Modernization WC. Cultural change and democracy: the human development sequence. Cambridge: Cambridge University Press, 2005.
27. Harrison MI. Implementing change in health systems: market reforms in the United Kingdom. Sweden and the Netherlands: Sage, 2004.

28. Javanparast S, Baum F, Labonte R, et al. Community health workers perspectives on their contribution to rural health and well-being in Iran. Am J Public Health 2011;101:2287-92.

29. Van Lerberghe W. The world health report 2008: primary health care: now more than ever: World Health Organization, 2008.

30. Organization WH. The world health report 2000: health systems: improving performance: World Health Organization, 2000.

31. Organization WH. The world health report 2006: working together for health: World Health Organization, 2006.

32. Tangcharoensathien V, Mills A, Palu T. Accelerating health equity: the key role of universal health coverage in the Sustainable Development Goals. BMC Med 2015;13:101.

33. Kenny C, Sumner A. More money or more development: what have the MDGs achieved? SSRN Electronic Journal 2011(278). 